\title{
Pengontrol Lampu Jarak Jauh Berbasis
}

\author{
Azis Surya Maheri, Heru Supriyono \\ Program Studi Informatika \\ Universitas Muhammadiyah Surakarta (UMS) \\ Surakarta, Indonesia \\ Azissuryam@gmail.com, Heru.Supriyono@ums.ac.id
}

\begin{abstract}
Abstraksi- Lampu merupakan salah satu peralatan elektronik yang digunakan untuk penerangan dengan memanfaatkan energi listrik. Sistem kontrol yang masih manual sering kali menjadi kendala menghidupkan dan mematikan lampu karena jarak antara saklar lampu satu dengan lainnya yang berjauhan sehingga membutuhkan waktu untuk menghidupkan lampu satu dengan lainnya. Berdasarkan permasalahan tersebut peneliti bertujuan ingin membangun sistem pengontrol lampu jarak jauh berbasis web dengan memanfaatkan teknologi VPN. Sistem ini dapat digunakan untuk mengontrol lampu dengan jarak jauh, mempermudah dalam manajemen penggunaan lampu, dan meningkatkan efisiensi waktu bagi pengguna. Penelitian ini menggunakan metode eksperimental dengan percobaan langsung pada jaringan lampu. Orange Pi Zero digunakan sebagai pengontrol, relay dihubungkan melalui GPIO menggunakan kabel jumper. Tampilan pengontrol berupa web yang diberikan perintahperintah, sehingga dapat mengontrol lampu yang terhubung dengan relay. OpenVPN dan firewall memungkinkan sistem pengontrol diakses secara public menggunakan web browser pada smartphone/laptop. Seluruh fungsi dalam sistem ini sesuai dengan harapan penulis berdasarkan pengujian yang menunjukkan nilai persentase $100 \%$.
\end{abstract}

Katakunci-lampu; penerangan; orange pi zero; relay; openvpn; iot; gpio

\section{Pendahuluan}

Ketergantungan manusia terhadap energi listrik sudah terlihat dari tahun ke tahun, dengan meningkatnya daya beli peralatan elektronik sehingga mempengaruhi penggunaan energi listrik. Di Indonesia, meningkatnya penggunaan listrik disertai dengan naiknya tarif listrik dari tahun ke tahun sehingga dengan adanya fenomena tersebut seharusnya manusia harus lebih bijak dalam memanfaatkan energi listrik. Lampu merupakan salah satu peralatan elektronik yang digunakan untuk penerangan dengan memanfaatkan energi listrik. Penggunaan lampu yang efektif dan efisien dapat menghemat penggunaan energi listrik. Sistem kontrol yang masih manual sering kali menjadi kendala menghidupkan dan mematikan lampu karena jarak antara saklar lampu satu dengan lainnya yang berjauhan sehingga membutuhkan waktu untuk menghidupkan lampu satu dengan lainnya. Sebagai contoh apabila mempunyai rumah dengan 2 lantai membutuhkan waktu yang lebih karena setelah menghidupkan di lantai satu harus menaiki tangga terlebih dahulu untuk menghidupkan lampu di lantai dua.

Perkembangan teknologi yang sangat cepat, memberikan solusi untuk mengatasi permasalahan tersebut. Teknologi yang berkembang saat ini cukup banyak diantaranya yaitu smart home dan internet of things. Dengan adanya smart home dan internet of things diharapkan dapat membantu manusia dalam mengontrol atau mengelola peralatan rumah. Menurut Gunge \& Yalagi (2016) smart home istilah lainnya adalah otomatisasi rumah tergolong teknologi baru yang didesain guna manusia dapat melakukan kegiatan dengan nyaman, aman, dan ekonomis. Kompenen otomatisasi rumah diantaranya, tampilan pengguna, transmiter, perangkat embedded, dan peralatan elektronik.

Menurut Kurniawan (2017) SMS Gateway dapat dimanfaatkan untuk mengontrol smart home dengan mengirimkan perintah melalui SMS dari smartphone ke modem yang terhubung mikrokontroler ATMega 8535 kemudian relay akan meneruskan perintah yang diterima mikrokontroler. Memanfaatkan jaringan wifi yang menjangkau gedung-gedung untuk mengendalikan lampu dan kipas angin yang ada dari jarak jauh (Hermawan, 2017).

Dahulu sistem kontrol peralatan elektronik belum banyak yang memanfaatkan jaringan internet atau VPN sebagai media transmisinya. Berdasarkan permasalahan tersebut peneliti bertujuan ingin membangun sistem "Pengontrol Lampu Jarak Jauh berbasis Web" dengan memanfaatkan teknologi VPN, sistem ini dapat digunakan untuk mengontrol lampu dengan jarak jauh, mempermudah dalam manajemen penggunaan lampu, dan meningkatkan efisiensi waktu bagi pengguna.

Menurut Madakam, Ramaswamy \& Tripathi (2015) objek dunia nyata akan berubah menjadi objek virtual dengan adanya internet of things dimasa yang akan datang. Internet of things akan menyatukan semua yang ada di dunia, memungkinkan manusia mengontrol perangkat yang berada disekitarnya dan mengetahui status perangkat secara realtime. Penelitian yang dilakukan oleh Supriyono, Widjaya, \& Supardi (2013) menyatakan VPN dapat menghubungkan satu titik dengan titik yang lain seperti memiliki jaringan pribadi, penggunaan VPN memperkecil terjadinya penyadapan dan pengrusakan data. Selain itu, dapat digunakan untuk remote desktop sehingga memungkinkan menyelesaikan pekerjaan kantor tanpa membawa pulang komputer.

Menurut Nugroho, Widada \& Kustanto (2015) dengan menggunakan VPN sebuah perusahaan menghubungkan dari 
kantor ke kantor lain, sehingga dapat melakukan pertukaran data dengan mudah dan aman.

\section{METODE}

Penelitian ini menggunakan metode eksperimental dengan percobaan langsung pada jaringan lampu. Dalam membuat sistem ini penulis melalui beberapa tahapan seperti analisa kebutuhan, perancangan perangkat keras dan lunak, dan pengujian sistem seperti pada gambar 1 .

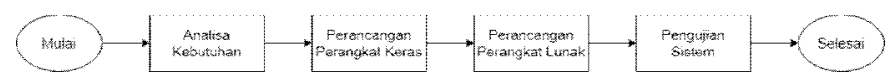

Gambar 1. Metode penelitian

\section{A. Analisa Kebutuhan}

Tahap pertama dalam penelitian ini mengumpulkan kebutuhan yang diperlukan sebagai pendukung dalam melakukan penelitian. Kebutuhan tersebut ada 2 jenis, yaitu kebutuhan perangkat keras, dan kebutuhan perangkat lunak seperti yang ditampilkan pada tabel I.

TABEL I. ANALISA KEBUTUHAN

\begin{tabular}{|c|c|}
\hline Perangkat Keras & Perangkat Lunak \\
\hline $\begin{array}{l}\text { Laptop AMD Quard Core } \\
\text { A10-7400P RAM 6GB HDD } \\
\text { 1TB }\end{array}$ & Pulpstone Openwrt \\
\hline $\begin{array}{l}\text { Orange Pi Zero H2 Quad- } \\
\text { core Cortex-A7 } \\
256 \mathrm{MB} / 512 \mathrm{MB} \text { DDR3 } \\
\text { SDRAM }\end{array}$ & Putty \\
\hline Adaptor $5 \mathrm{~V} / 2 \mathrm{~A}$ & WinSCP \\
\hline MicroSD $16 \mathrm{~GB}$ & uHTTPd webserver \\
\hline Relay Module 5V 4 channel & OpenVPN client \\
\hline Lampu \& fitting 3 buah & MySQL server \\
\hline Kabel LAN & CorelDRAW X7 \\
\hline Kabel Jumper & VPS \\
\hline Kabel listrik & Sublime Text 3 \\
\hline Steker & \\
\hline
\end{tabular}

\section{B. Perancangan Perangkat Keras}

Tahap yang kedua adalah perancangan perangkat keras berisi gambaran rangkaian perangkat yang akan digunakan, penelitian ini membutuhkan komponen antara lain Smartphone/Laptop sebagai client, VPS (Virtual Private Server), Orange Pi Zero, Relay Module 5V 4 channel, dan 3 buah fitting dan lampu. Penulis menyewa VPS (Virtual Private Server) selama 1 bulan agar Orange Pi Zero dapat dikenali secara public sehingga dapat diakses darimana saja asalkan client terhubung dengan internet. Pada relay terdapat 6 PIN terdiri dari ground, vcc, dan 4 pin input yang mana ground dihubungkan ke ground, vcc ke vcc, pin input dihubungkan ke pin output yang terdapat pada Orange Pi Zero menggunakan kabel jumper, kemudian pada lampu ke relay dan steker dihubungkan menggunakan kabel listrik lebih jelasnya seperti diagram blok rangkaian pada gambar 2 .

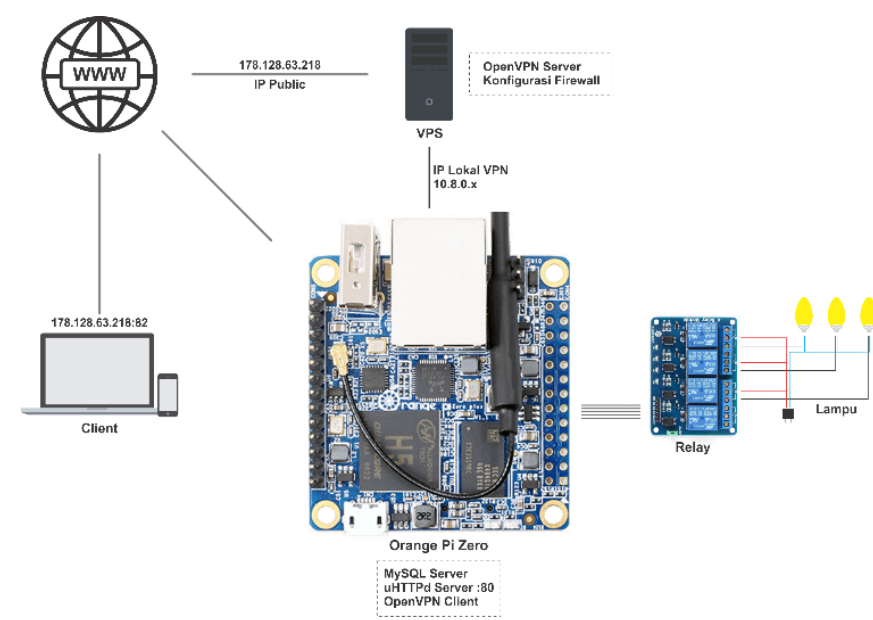

Gambar 2. Diagram blok rangkaian

Tabel 2 dan 3 menunjukkan PIN yang digunakan untuk saling terhubung antara Orange Pi Zero dengan relay.

TABEL II. PIN ORANGE PI ZERO KE RELAY

\begin{tabular}{|c|c|}
\hline Orange Pi Zero & Relay \\
\hline PIN 4 (5V) & PIN 6 (VCC) \\
\hline PIN 6 (GND) & PIN 1 (GND) \\
\hline PIN 3 & PIN 2 (IN1) \\
\hline PIN 5 & PIN 3 (IN2) \\
\hline PIN 7 & PIN 4 (IN3) \\
\hline
\end{tabular}

TABEL III. OUTPUT RELAY KE LAMPU

\begin{tabular}{|c|c|}
\hline Relay & Lampu \\
\hline IN1 & Lampu 1 \\
\hline IN2 & Lampu 2 \\
\hline IN3 & Lampu 3 \\
\hline
\end{tabular}

\section{Perancangan Perangkat Lunak}

Tahap ini mensimulasikan alur kerja dari hasil perancangan perangkat keras. Pada VPS (Virtual Private Server) diinstal OpenVPN Server dan melakukan konfigurasi dengan menggunakan port 1194 dan jalur TCP yang akan digunakan sebagai server vpn oleh Orange Pi Zero, kemudian atur firewall untuk mengatur lalu lintas yang menuju port 80 (webserver) pada jaringan lokal akan dialihkan ke port 82 dapat dilihat pada gambar 3 - 4 . 


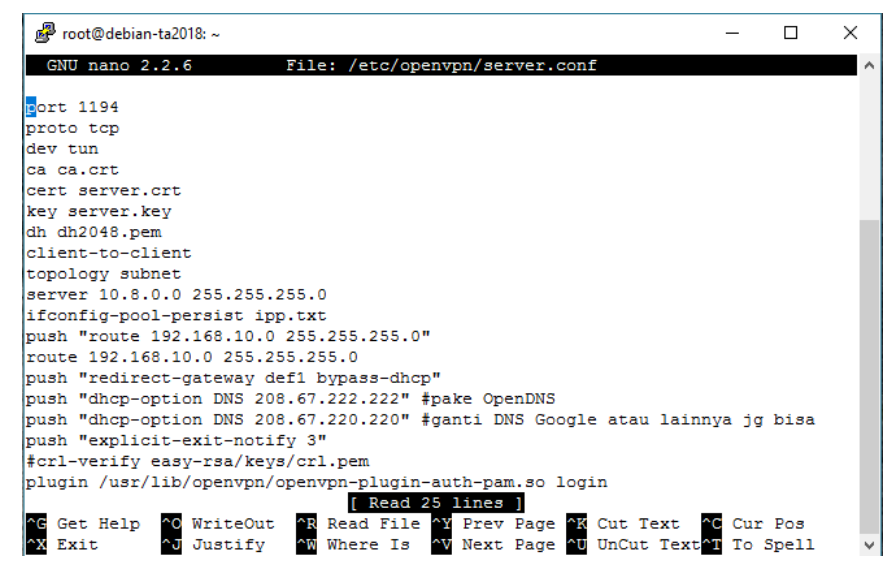

Gambar 3. Konfigurasi OpenVPN Server

iptables -F

iptables - $t$ nat $-\mathrm{A}$ POSTROUTING -0 etho $-j$ MASQUERADE

iptables -A PREROUTING - $t$ nat $-i$ etho -p tcp --dport 26 -j DNAT --to 10.8.0.4:22 82 -j DNAT --to $10,8,0,4: 80$ \#iptables $-t$ nat $-\mathrm{A}$ POSTROUTING -0 etho -3 10.8.0.0/24 -j MASQUERADE

exit 0

\section{Gambar 4. Aturan firewall di VPS}

Pada Orange Pi Zero diinstal sistem operasi Pulpstone Openwrt, dimana sistem operasi tersebut sudah terdapat paket aplikasi seperti uHTTPd Server berfungsi sebagai webserver untuk membuat tampilan berbasis web yang akan tampil halaman ketika client mengakses sistem tersebut, dan OpenVPN Client digunakan untuk direct remote agar web dapat diakses secara public. Kemudian menginstal MySQL Server untuk membuat akun pengguna untuk login ke web tersebut, lalu membuat sebuah database dan tabel seperti gambar 5 .

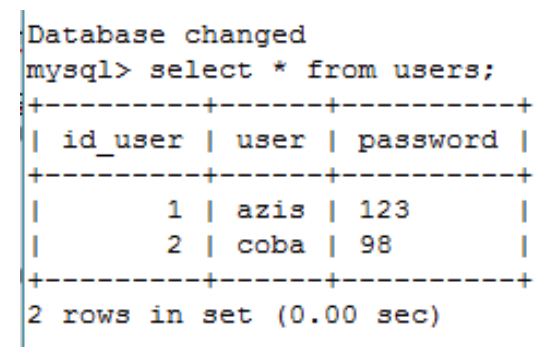

Gambar 5. Tabel daftar pengguna pada database

Selanjutnya seperti pada gambar 6 menginisialisasikan pin gpio sebagai output yang akan dihubungkan dengan pin input pada relay, sehingga semua output dari pin tersebut akan di teruskan ke pin input yang ada pada relay.

\section{GNU nano 2.4.1}

\section{File: /etc/rc.local}

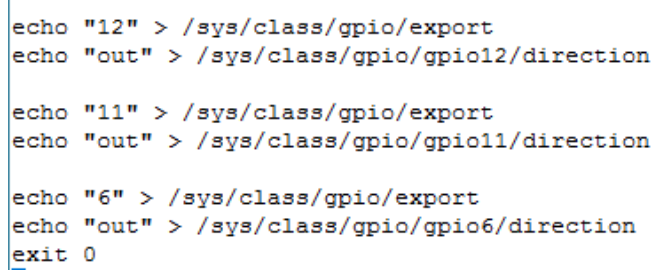

Gambar 6. Inisialisasi GPIO
Pembuatan halaman web menggunakan bahasa HTML, PHP dan untuk proses pembuatan halaman tersebut seperti gambar 7 dengan aplikasi Sublime Text 3. Web tersebut terdiri dari halaman login, halaman awal, halaman kontrol, dan halaman tentang.

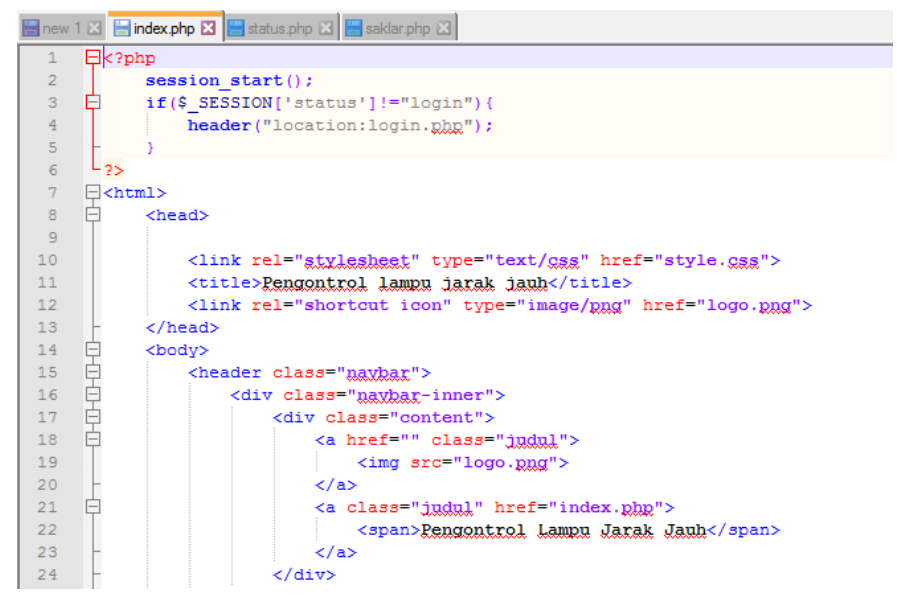

Gambar 7. Proses edit halaman web

Selanjutnya membuat konfigurasi openvpn client dan file pass.txt yang didalamnya berisi user dan password yang disimpan satu folder dengan konfigurasi tersebut di Orange Pi Zero seperti gambar 8 .

GNU nano 2.4.1

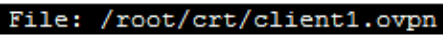

client

dev tun

proto tcp

remote 178.128 .63 .2181194

resolv-retry infinite

nobind

; user nobody

; group nogroup

persist-key

persist-tun

; ca ca.crt

; cert client.crt

; key client.key

remote-cert-tls server

comp-1zo

auth-user-pass /root/crt/pass.txt

verb 3

Gambar 8. Konfigurasi OpenVPN client pada Orange Pi Zero

Kemudian Orange Pi Zero dihubungkan dengan internet, setelah itu menjalankan OpenVPN client seperti gambar dibawah ini.

rootborangePiZero: \# openvpn/root/crt/client1.ovpn

Gambar 9. Menjalankan OpenVPN client

Lalu smartphone atau laptop yang sudah terhubung dengan internet kemudian mengakses 178.128.63.218:82 dengan web browser. Maka akan muncul halaman login, jika data benar akan menuju halaman kontrol lampu namun apabila data salah terjadi error dan kembali ke halaman login. Pada halaman tersebut terdapat tombol untuk menghidupkan atau mematikan 
lampu. Tombol tersebut terdapat perintah yang terintegrasi dengan Orange Pi Zero, kemudian perintah akan diteruskan ke relay. Apabila relay bernilai 0 ketika tombol ditekan maka lampu akan menyala namun jika relay bernilai 1 dan tombol ditekan lampu akan mati untuk lebih jelasnya ditampilkan pada gambar 10 .

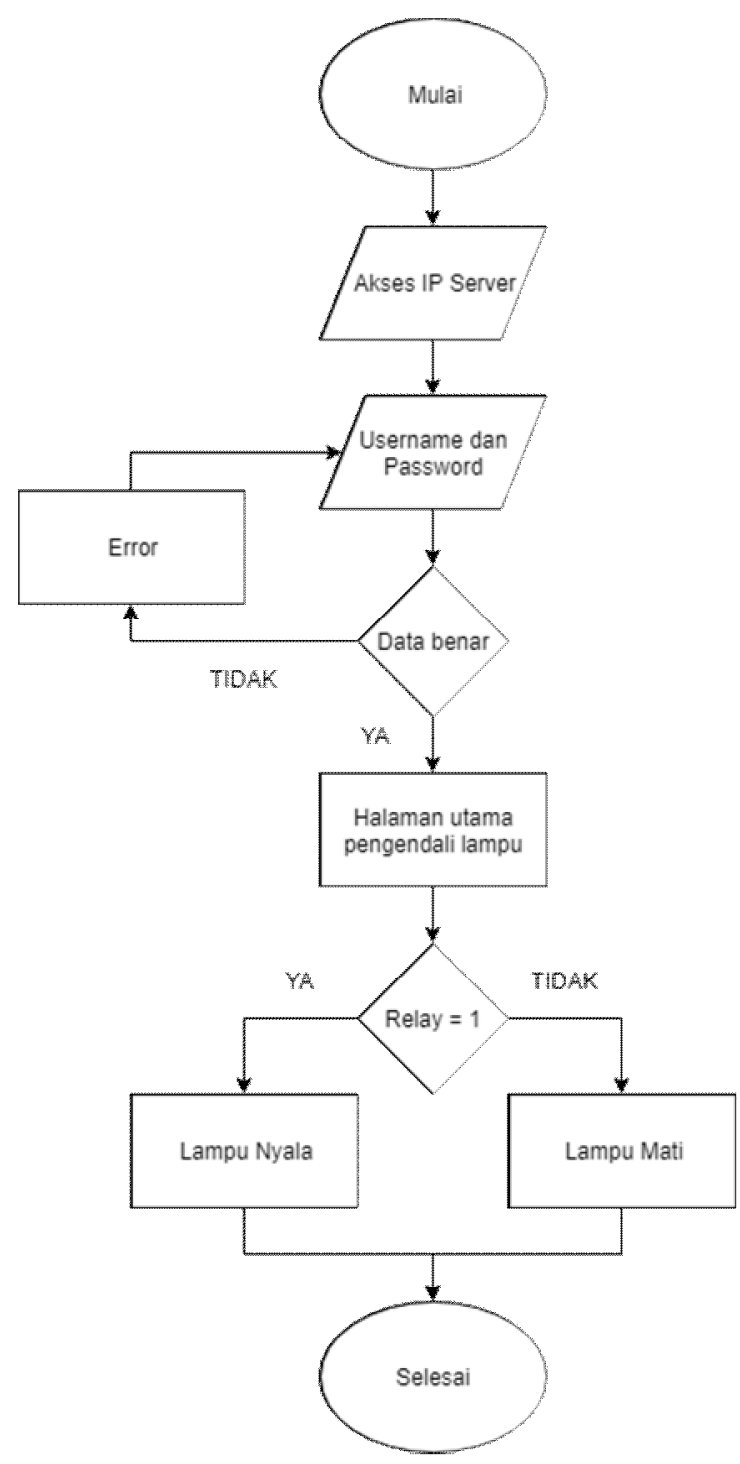

Gambar 10. Diagram alur sistem

\section{Pengujian Sistem}

Tahap ini dilakukan untuk menguji sistem sudah sesuai dengan diagram alur yang telah dibuat, dengan cara menguji perangkat keras dan lunak sudahkah sesuai dengan fungsi masing-masing. Pengujian perangkat keras dengan mengecek semua instalasi kabel yang terhubung antar perangkat, dan mengakses 178.128.63.218:82 dengan melalui internet untuk membuka halaman pengontrol lampu.

\section{HASIL DAN PEMBAHASAN}

Hasil yang telah tercapai adalah sebuah rangkaian sistem embedded yang terlihat pada gambar 11, rangkaian tersebut terdiri dari Orange Pi Zero, MicroSD 16GB, Adaptor 5V/2A, Relay Module 5V 4 channel, Lampu \& fitting 3 buah, kabel listrik, dan kabel jumper. Pada Orange Pi Zero telah diinstall sistem operasi Pulpstone Openwrt, webserver uHTTPd, MySQL server, OpenVPN Client, dan sebuah web yang dibuat menggunakan HTML, PHP yang terdiri dari halaman login, halaman awal, halaman pengontrol lampu, dan halaman tentang.

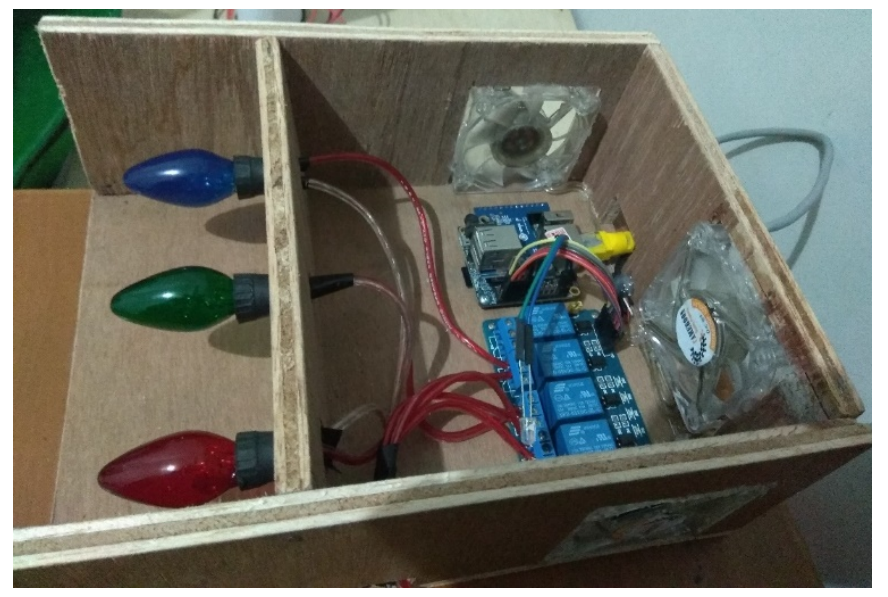

Gambar 11. Rangkaian sistem embedded pengontrol lampu jarak jauh

Pada halaman login seperti gambar 12 di form username dan password diisi sesuai daftar pengguna yang ada pada tabel "users" di database "pengguna" jika username dan password benar maka akan otomatis masuk ke halaman awal yang berisi fungsi mengenai sistem pengontrol lampu jarak jauh seperti gambar 14, namun apabila salah pada bagian bawah tombol login akan muncul tulisan "username dan password tidak sesuai" dapat dilihat pada gambar 13 .

\section{(1) PENGONTROL LAMPU JARAK JAUH}

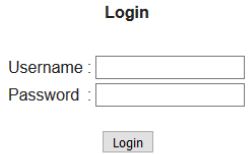

Gambar 12. Tampilan login

\section{PENGONTROL LAMPU JARAK JAUH}

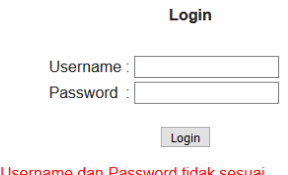

Gambar 13. Salah memasukkan username dan password 


\section{PENGONTROL LAMPU JARAK JAUH}

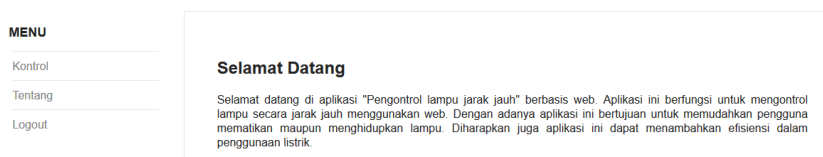

Gambar 14. Tampilan halaman awal

Halaman kontrol yang dapat dilihat pada gambar 15 digunakan untuk mengontrol lampu yang terhubung dengan relay, dan secara otomatis mendeteksi apakah lampu dalam keadaan hidup maka pada tombol lampu akan otomatis "on" namun jika mati maka terjadi sebaliknya. Jika diasumsikan kondisi awal lampu mati ketika tombol "off" ditekan maka tombol akan menjadi "on" dan lampu akan hidup, bila ingin mematikan tekan tombol "on" akan berubah menjadi "off" kemudian lampu mati.

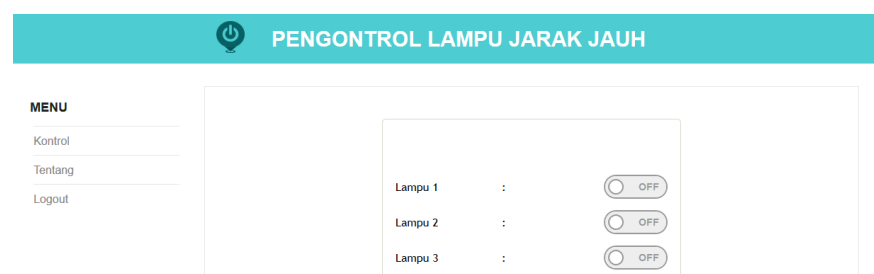

Gambar 15. Tampilan halaman pengontrol lampu

Halaman tentang berisi alat dan bahan yang digunakan untuk membuat sistem pengontrol lampu jarak jauh yang dapat dilihat pada gambar 16 .

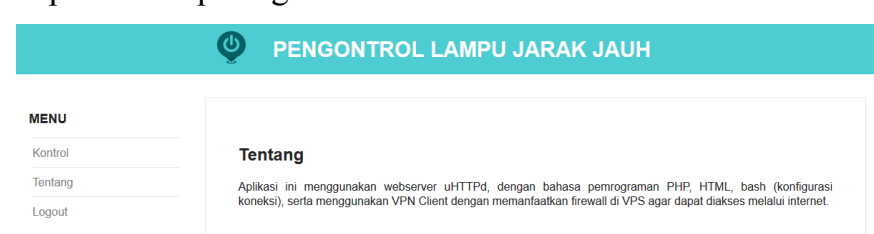

Gambar 16. Tampilan halaman tentang

Tabel 4 pengujian dilakukan dengan 10 kali percobaan, dalam percobaan tersebut tombol berjalan sesuai fungsinya masing-masing dengan persentase $100 \%$.

TABEL IV. PENGUJIAN FUNGSI TOMBOL PADA WEB

\begin{tabular}{|c|c|c|c|}
\hline $\begin{array}{c}\text { Nama } \\
\text { Tombol }\end{array}$ & Berhasil & $\begin{array}{c}\text { Tidak } \\
\text { berhasil }\end{array}$ & Persentase \\
\hline Tombol login & 10 & 0 & $100 \%$ \\
\hline $\begin{array}{c}\text { Tombol } \\
\text { kontrol }\end{array}$ & 10 & 0 & $100 \%$ \\
\hline $\begin{array}{c}\text { Tombol } \\
\text { tentang }\end{array}$ & 10 & 0 & $100 \%$ \\
\hline Tombol on & 10 & 0 & $100 \%$ \\
\hline Tombol off & 10 & 0 & $100 \%$ \\
\hline
\end{tabular}

Pengujian tabel 5 dilakukan menggunakan perangkat yang berbeda, yaitu laptop dan smartphone. Dari pengujian tersebut didapati presentase keberhasilan $100 \%$, dimana tomboltombol yang ada di web dapat digunakan sesuai fungsi masing-masing ketika diakses melalui smartphone atau laptop.
TABEL V. PENGUJIAN MENGGUNAKAN PERANGKAT YANG BERBEDA

\begin{tabular}{|c|c|c|c|c|}
\hline Perangkat & $\begin{array}{c}\text { Halaman } \\
\text { Login }\end{array}$ & $\begin{array}{c}\text { Halaman } \\
\text { Kontrol }\end{array}$ & $\begin{array}{c}\text { Halaman } \\
\text { Tentang }\end{array}$ & Persentase \\
\hline Laptop & Berhasil & Berhasil & Berhasil & $100 \%$ \\
\hline Smartphone & Berhasil & Berhasil & Berhasil & $100 \%$ \\
\hline
\end{tabular}

Pengujian tabel 6 untuk mengetahui perbedaan waktu dibutuhkan untuk menyalakan lampu secara manual dan menggunakan sistem pengontrol lampu jarak jauh. Dari pengujian tersebut didapati dengan cara manual untuk menghidupkan lampu dengan jarak 20 meter dibutuhkan waktu 32 detik, 40 meter dibutuhkan 1 menit 5 detik, dan 60 meter dibutuhkan waktu 1 menit 40 detik. Sedangkan dengan menggunakan sistem pengontrol lampu jarak jauh ini hanya membutuhkan waktu 2 detik untuk menghidupkan lampu dengan jarak 20 meter, 40 meter, dan 60 meter. Sehingga disimpulkan bahwa penggunaan sistem pengontrol lampu jarak jauh dapat menimbulkan efisiensi waktu bagi pengguna untuk menghidupkan dan mematikan lampu.

TABEL VI. PERBANDINGAN WAKTU MENGHIDUPKAN SECARA MANUAL DAN MENGGUNAKAN SISTEM

\begin{tabular}{|c|c|c|}
\hline Metode & Jarak & Waktu \\
\hline \multirow{3}{*}{ Manual } & $10 \mathrm{~m}$ & 32 detik \\
\cline { 2 - 3 } & $20 \mathrm{~m}$ & 1 menit 5 detik \\
\cline { 2 - 3 } & $30 \mathrm{~m}$ & 1 menit 40 detik \\
\hline \multirow{3}{*}{ Sistem } & $10 \mathrm{~m}$ & 2 detik \\
\cline { 2 - 3 } & $20 \mathrm{~m}$ & 2 detik \\
\cline { 2 - 3 } & $30 \mathrm{~m}$ & 2 detik \\
\hline
\end{tabular}

Gambar 17 menunjukkan perangkat keras dan sistem pengontrol lampu jarak jauh telah dapat terhubung dengan baik, sehingga ketika tombol "on" atau "off” ditekan akan bereaksi terhadap lampu.

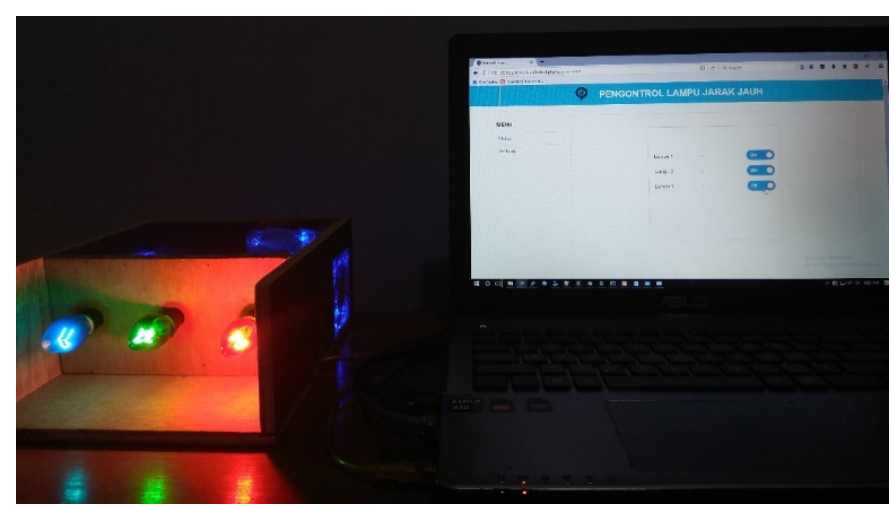

Gambar 17. Hasil pengujian rangkaian sistem pengontrol lampu jarak jauh

\section{PENUTUP}

Dari hasil penelitian yang dilakukan sistem pengontrol lampu jarak jauh menggunakan Orange Pi Zero dan VPN dapat berjalan sesuai dengan fungsinya dimana lampu dapat 
dihidupkan atau dimatikan dari jarak jauh, berdasarkan pengujian fungsi tombol pada web dapat berjalan lancar $100 \%$. Sehingga diharapkan sistem ini dapat mempermudah pengguna dalam manajemen penggunaan lampu yang akan meningkatkan efisiensi waktu pengguna untuk menghidupkan dan mematikan lampu.

Penulis menyarankan agar kedepannya sistem ini tidak hanya digunakan untuk lampu saja, namun dapat digunakan untuk alat elektronik lainnya. User interface dapat dikembangkan dengan berbasis android, sehingga tampilan lebih interaktif dan responsive.

\section{Daftar Pustaka}

[1] Gunge, V. S., \& Yalagi, P. S. 2016. Smart Home Automation: A Literature Review. IJCA Proceedings on National Seminar on Recent Trends in Data Mining, RTDM 2016, 2 (3), 6-10. ISSN 0975 - 8887.
[2] Kurniawan, A. T. 2017. Perancangan Sistem Pengendali Lampu berbasis SMS Gateway dengan mikrokontroler ATmega 8535. Prosiding Seminar Nasional Inovasi Teknologi - SNITek 2017, Mei, Jakarta. ISSN 2580-5495.

[3] Madakam, S., Ramaswamy, R., \& Tripathi, S. 2015. Internet of Things (IoT): A Literature Review. Journal of Computer and Communications, 3, 2015, 164-173.

[4] Supriyono, H., Widjaya, J. A., \& Supardi, A. (2013). Penerapan Jaringan Virtual Pivate Network Untuk Keamanan Komunikasi Data Bagi PT. Mega Tirta Alami. WARTA, 16 (2), 88-101. ISSN: 1410-9344.

[5] Hermawan, D. 2017. Pengendali Lampu dan Kipas Angin dari Jarak Jauh dengan Wifi dan Raspberry Pi. Informatika. Fakultas Komunikasi dan Informatika. Universitas Muhammadiyah Surakarta.

[6] Nugroho, I., Widada, B., \& Kustanto. 2015. Perbandingan Performansi Jaringan Virtual Private Network Metode Point To Point Tunneling Protocol (PPTP) Dengan Metode Internet Protocol Security. Jurnal TIKomSiN, 3 (2). ISSN : 2338-4018. 